\title{
Role of Ag1+ substitutional defects on the electronic and optical properties of n-type CdS thin films semiconductor for sustainable and stable window layer in solar cells technology
}

DOI:

10.1016/j.optmat.2018.08.056

\section{Document Version}

Accepted author manuscript

Link to publication record in Manchester Research Explorer

\section{Citation for published version (APA):}

Mahmood, W., Ali, J., Thomas, A., Awan, S. U., Jackman, M., Haq, A., Hassan, M. U., \& Shah, N. A. (2018). Role of Ag1 + substitutional defects on the electronic and optical properties of $n$-type $\mathrm{CdS}$ thin films semiconductor for sustainable and stable window layer in solar cells technology. Optical Materials.

https://doi.org/10.1016/j.optmat.2018.08.056

\section{Published in:}

Optical Materials

\section{Citing this paper}

Please note that where the full-text provided on Manchester Research Explorer is the Author Accepted Manuscript or Proof version this may differ from the final Published version. If citing, it is advised that you check and use the publisher's definitive version.

\section{General rights}

Copyright and moral rights for the publications made accessible in the Research Explorer are retained by the authors and/or other copyright owners and it is a condition of accessing publications that users recognise and abide by the legal requirements associated with these rights.

\section{Takedown policy}

If you believe that this document breaches copyright please refer to the University of Manchester's Takedown Procedures [http://man.ac.uk/04Y6Bo] or contact uml.scholarlycommunications@manchester.ac.uk providing relevant details, so we can investigate your claim.

\section{OPEN ACCESS}


Materials

Elsevier Editorial System(tm) for Optical

Manuscript Draft

Manuscript Number: OM-D-18-01268R1

Title: Role of Agl+ Substitutional Defects on the Electronic and Optical Properties of n-type CdS Thin Films Semiconductor for sustainable and Stable Window Layer in Solar Cells Technology

Article Type: Original Research

Keywords: CSS technique,

cdS thin films,

Silver doping,

optical properties,

XPS study,

Sustainable Energy

Corresponding Author: Dr. Dr. Waqar Mahmood,

Corresponding Author's Institution: Fatima Jinnah Women University

First Author: Dr. Waqar Mahmood

Order of Authors: Dr. Waqar Mahmood; Junaid Ali, PhD; Andrew Thomas, PhD; Saif ullah Awan, PhD; Mark Jackman, PhD; Anwar -ul-Haq, PhD; Mohammad Umair Hassan, PhD; Nazar Abbas Shah, PhD

Abstract: Cadmium sulfide (CdS) has been investigated extensively for II generation solar cell as an efficient window layer with $n$ type conductivity. The significance of CdS is because of its large energy band gap tune-ability and native n-type conductivity. In this report, energy band gap engineering of CdS films was carried out by means of controlled silver (Ag) doping to modify their optical properties along with electrical properties. Closed space sublimation (CSS) technique has been employed to synthesize as-deposited CoS thin films. One of the advantages of CSS grown films is roughness which offers more trapping/absorbing of light. Ion exchange solution process was carried out for Ag-doping, which resulted in widening of the band gap from $2.15 \mathrm{eV}$ to a value of $2.45 \mathrm{eV}$, showing the increased capability of solar energy harvesting. Un-doped CdS thin films showed a high resistivity of the order of $106 \Omega-\mathrm{cm}$, which reduced to only $102 \Omega-\mathrm{cm}$ with the Ag-doping, as probed by four-point probe, offering great advantage for the system to be used in II-VI solar cells. Un-doped and Ag-doped films showed n-type conductivity. We studied the Ag-doping effects on the surface morphological and correlated the morphological modification with changing optical and electrical behaviour of CdS thin films. It is believed that enhanced properties offer great potential for these films to be used for the solar cell applications. 


\title{
Role of $\mathrm{Ag}^{1+}$ Substitutional Defects on the Electronic and Optical Properties of $n$-type CdS Thin Films Semiconductor for Sustainable and Stable Window Layer in Solar Cells Technology
}

Waqar Mahmood ${ }^{1,2,3}{ }^{*}$, Junaid Ali ${ }^{4}$, Andrew Thomas ${ }^{2,5}$, Saif ullah Awan ${ }^{6}$, Mark Jackman ${ }^{2}$, Anwar-ul-Haq ${ }^{7}$, M. Umair Hassan ${ }^{4}$, Nazar Abbas Shah ${ }^{3}$

1. Material Synthesis \& Characterizations (MSC) Laboratory, Department of Physics, Fatima Jinnah Women University (FJWU), The Mall Rawalpindi-Pakistan.

2. Photon Science Institute (PSI), School of Physics and Astronomy, University of Manchester, Oxford Road, M13 9PL Manchester-United Kingdom.

3. Thin Films Technology (TFT) Research Laboratory, Department of Physics, COMSATS Institute of Information Technology (CIIT), Islamabad-Pakistan.

4. Optoelectronic Research Laboratory (OERL), Department of Physics, COMSATS Institute of Information Technology (CIIT), Islamabad-Pakistan.

5. School of Materials, University of Manchester, Oxford Road, M13 9PL Manchester-United Kingdom.

6. Department of Electrical Engineering, NUST College of Electrical and Mechanical Engineering, National University of Science and Technology (NUST), Islamabad 54000, Pakistan.

7. Department of Physics, Govt. Postgraduate College Satellite Town (Boys), Rawalpindi-Pakistan.

*waqarmahmood@,fjwu.edu.pk

\begin{abstract}
Cadmium sulfide (CdS) has been investigated extensively for II generation solar cell as an efficient window layer with $\mathrm{n}$ type conductivity. The significance of $\mathrm{CdS}$ is because of its large energy band gap tune-ability and native n-type conductivity. In this report, energy band gap engineering of CdS films was carried out by means of controlled silver (Ag) doping to modify their optical properties along with electrical properties. Closed space sublimation (CSS) technique has been employed to synthesize as-deposited CdS thin films. One of the advantages of CSS grown films is roughness which offers more trapping/absorbing of light. Ion exchange solution process was carried out for Ag-doping, which resulted in widening of the band gap from $2.15 \mathrm{eV}$ to a value of $2.45 \mathrm{eV}$, showing the increased capability of solar energy harvesting. Un-doped CdS thin films showed a high resistivity of the order of $\sim 10^{6} \Omega$ $\mathrm{cm}$, which reduced to only $\sim 10^{2} \Omega$-cm with the Ag-doping, as probed by four-point probe, offering great advantage for the system to be used in II-VI solar cells. Un-doped and Agdoped films showed n-type conductivity. We studied the Ag-doping effects on the surface morphological and correlated the morphological modification with changing optical and electrical behaviour of CdS thin films. It is believed that enhanced properties offer great potential for these films to be used for the solar cell applications.
\end{abstract}

Keywords: CSS technique, Silver doping, Optical properties, XPS Study, Sustainable Energy 


\section{Introduction}

II-VI semiconductor family has received a lot of attraction for their tunable optical and electrical properties [1-4]. Cadmium sulfide (CdS) is a member of II-VI chalcogenide semiconductor family. It is a potential candidate for extensively uses in the technology of optoelectronics, photovoltaic and photo catalysis devices because of its amazing electrical and optical properties (i.e. emission in visible range) [2-4]. Other great impending applications include its usage as photo detectors, optical filters, solar cells applications and photo-resistive switches [4-6]. CdS has good luminescence with high absorption coefficient and attracted much interest because of its high photoconductivity in the visible region due to its direct band gap transition type. The energy band gap at room temperature is $2.42 \mathrm{eV}$ and refractive index 2.52. In electrical point of view, $\mathrm{CdS}$ has resistivity $\sim 10^{6} \Omega$-cm, n-type conductivity, high electron affinity and easy ohmic contact due to sulfur vacancies and cadmium interstitials. CdS exhibits both, cubic and hexagonal phases, which depends mainly on the selection of the synthesis route and growth parameters [7-10].

Metals doping plays a vital role in II-VI semiconductors due to reduction in electrical resistivity as well as tailoring optical properties for significant solar cell applications. The excitation wavelength and photoluminescence emission may also be dependent on metal dopants as it enhances the photo induced electron acceptors for betterment of photo catalysis capacity. Group I elements like gold $(\mathrm{Au})$, Copper $(\mathrm{Cu})$ and silver $(\mathrm{Ag})$ are the potential candidates as a dopants in II-VI semiconductors due to energy band gap engineering, resistivity reduction as well as structural changes [2-8]. The current research work deals with Ag dopant in CdS thin films. Ag as a dopant, can modify the electrical, optical and structural properties of $\mathrm{CdS}$ thin films at room temperature. Ion exchange process is a simplest way to immerse $\mathrm{Ag}$ into $\mathrm{CdS}$ thin films. The electron transport between $\mathrm{Ag}$ and $\mathrm{CdS}$ assisted due to variation in the fermi level of $\mathrm{Ag}$ and conduction band of CdS thin films.

$\mathrm{CdS}$ is used as an efficient window layer in CdTe based solar cell due to its wide band gap energy with low absorption, high conversion efficiency and direct band gap transition. Since the ultraviolet region has higher energy than the CdS energy band gap, so it is strongly absorbed. However, visible and near infrared regions are transmitted completely (500-2000 $\mathrm{nm})$. For this reason, $\mathrm{CdS}$ is considered as a good window layer material for both visible as well as infrared regions. The property of high tuneablity of CdS band gap via doping can be exploited in order to further enhance the optical properties of the window layer. Another 
important requirement for the window layer material is that it should exhibit low resistivity. Fortunately, the relatively high resistivity of $\mathrm{CdS}$ can also be reduced significantly via a suitable doping and controlling the synthesis parameters. $16.5 \%$ of efficiency has been reported so far for $\mathrm{CdTe} / \mathrm{CdS}$ heterojunction solar cell using closed space sublimation (CSS) technique [11].

The other CdS synthesis techniques have been reported to make CdS films, including thermal vacuum evaporation, Chemical bath deposition, chemical vapor deposition, spray pyrolysis metal organic etc. Whereas in order to carry out the required doping, ion exchange doping has been found very useful. The ion exchange process facilitates the addition of doped material into CdS thin films at substitution sites and/or interstitial sites, depending upon the availability of size of atoms and vacancies sites. The synthesis and doping processes are cost effective, inexpensive and easy to use. The ion exchange process is a random chemical process.

In this paper, we used the CSS technique to grow CdS thin films, the as-deposited thin films are rough with this synthesis technique, which is beneficial for enhanced light entrapment applications. CSS also facilitated efficient use of source materials due to a small distance between the source and substrate, without compromising on the quality film for solar cell applications [3-5]. The Ag-doping was carried out using ion exchange method, and doping effects on physical properties of $\mathrm{CdS}$ thin films have been investigated. The correlation between the morphology and optical properties as well as the electrical properties in Ag-doped and un-doped CdS thin films were studied here.

\section{Experimental Section}

CdS powder (99.99\%, Aldrich) was thermally sublimated on commercial soda lime glass slide $\left(7.5 \times 2.5 \times 0.5 \mathrm{~cm}^{3}\right)$ to form as-deposited $\mathrm{CdS}$ thin-films. The deposition was done under high vacuum $\left(10^{-5}\right.$ mbar) in a close spaced sublimation configuration [1-3, 12]. Source and substrate temperatures were optimized at $600^{\circ} \mathrm{C}$ and $450^{\circ} \mathrm{C}$ (with 5 min of deposition time) for the desired quality of the films. Source-substrate distance was kept fixed at $5 \mathrm{~mm}$ for good quality of films. A thin mica sheet between the graphite boat and substrate was placed for temperature gradient. Mica sheet having a hole to pass source material to substrate. A graphite boat was used to sublimate the CdS source material and the substrate was attached to a heated graphite slab to obtain a uniform heat distribution across the entire 
substrate during sublimation process. In order to heat the source material, a 1000W (ac. 220 V) halogen lamp was used with a control power supply. Another halogen lamp of $500 \mathrm{~W}$ (ac. $\sim 220 \mathrm{~V}$ ) with a control supply was used to heat the substrate. The temperatures for both, the source and the substrate, were recorded using two separate K-type thermocouples attached to their corresponding assemblies. After depositing the films, the source lamp was switched off and the substrate lamp was left on (for annealing) until the source temperature dropped to that of the substrate temperature. Subsequently, the substrate heater was switched off and left for another hour for the entire chamber to cool down to the room temperature. The vacuum was not broken during entire cooling process took place at same/unaltered vacuum conditions.

After the deposition process, CdS thin films were doped with $\mathrm{Ag}$ using the ion exchange method. The ions were exchanged chemically and it is a random process and cannot be controlled. Films were immersed in a $0.1 \mathrm{~g} / 100 \mathrm{ml}$ concentrated solution of $\mathrm{Ag}\left(\mathrm{NO}_{3}\right)_{2}$ for optimized time of 10,20 and 30 minutes, thus distinguishing doping of one sample from the other. These doping time were optimized and after $30 \mathrm{~min}$ the film adherence not supported for further doping. After the immersion, these films were dried in air and annealed at $350^{\circ} \mathrm{C}$ for one hour for $\mathrm{Ag}$ diffusion into $\mathrm{CdS}$ thin films to take place.

Optical properties including optical band gap, film thickness and refractive index were investigated using transmission spectra between wavelength range of $300<\lambda<2000 \mathrm{~nm}$, recorded using UV-VIS-NIR spectrophotometer (Perkin Elmer Lambda 950). UV Win lab software was used to measure the transmission of thin films. The morphology of the CdS thin-film samples was studied using Scanning Electron Microscopy (SEM, LSM-6490A) and Atomic Force Microscopy (AFM). The structural characterization of Ag-doped samples was carried out by XRD using $\mathrm{Cu} \mathrm{K \alpha}(1.5418 \AA$ ) radiation. X-rays photoelectron spectroscopy (XPS) was employed to investigate the doping profile within the film structure.

\section{Results and discussion}

\section{Structural Study}

The crystal structure and crystalline quality of thin films were investigated using X-ray diffraction (XRD) technique with diffraction angle ranging from $20^{\circ}$ to $80^{\circ}$. Fig. 1 . shows XRD diffracted patterns of as-deposited and Ag-doped CdS samples. The reflection peaks obtained for all thin film samples match well with the indexed to the hexagonal structural phase of CdS (JCPDS card no. 41-1049). Two major diffracted planes (002) and (103) are the 
most prominent as compared to other diffracted planes. We did not observe any secondary phases or metal peaks from XRD analysis of all samples. There were no other peaks corresponding to metallic $\mathrm{Ag}^{0}$, which can be related to low amounts or absence of impurity.

We found that the intensities of the diffraction corresponds the planes in different samples are almost same, as the strongest reflection of (002) plane in all samples at $2 \theta$ diffraction angle $26.65^{\circ}( \pm 0.03)$ with varying the Ag concentration. The XRD planes (002) and (103) are more enlarged view in Fig. 2. respectively. After incorporating the Ag in CdS thin film, the peaks shift towards higher angled values. These calculations show that the overall crystal structure of CdS system expands as the Ag dopant is immersed in thin film samples. Since the cationic size of $\mathrm{Ag}^{1+}\left(1.26^{\circ} \mathrm{A}\right)$ is smaller than the $\mathrm{Cd}^{2+}\left(0.97^{\circ} \mathrm{A}\right)$, so the expansion of crystal size after incorporating the Ag contents in $\mathrm{CdS}$ thin films is our expected result as we extracted from XRD data. The crystallite size was calculated using Sherrer formula [13]:

$$
D=\frac{k \lambda}{\beta \cos \theta}
$$

Where, $k$ : wavelength is taken as 0.9 and $\beta$ is the full width half maximum (FWHM) and $\theta$ : Bragg's angle in degrees in correspondence to the maximum peak intensity. The crystallite sizes of the samples were calculated in the range of $20-30 \mathrm{~nm}$. Typically, the crystallite size is dependent on the annealing temperature, film thickness, deposition rate and substrate temperature $[5,10,14-16]$.

\section{Morphological Study}

Microstructure of as deposited CdS and Ag-doped CdS thin films were studied by scanning electron microscopy (SEM) Fig. 3 (a-d). Presents the surface morphology of doped and as-deposited $\mathrm{CdS}$ thin films. Grain size of $\mathrm{CdS}$ depends upon annealing time of thin films. The grains were progressively enhanced after Ag-immersion with subsequent annealing. In principle, after Ag-doping through ion-exchange, the silver ions diffuse into $\mathrm{CdS}$ and most likely organized themselves at interstitial positions. These ions displaced some of the $\mathrm{Cd}$ species and made $\mathrm{Ag}$ ions on interstitial positions later, as a result $\mathrm{Ag}_{2} \mathrm{~S}$ formed. The annealing process supports the crystal forming of $\mathrm{Ag}_{2} \mathrm{~S}$ and this effect reorients the microstructure. A clear and significant increase is shown in the SEM micrographs after Agdoping. Furthermore, the surface of CdS thin films lost smoothness in small quantity after immersion of Ag. Voids can be seen in as deposited CdS thin films, after Ag immersion these 
voids were filled with Ag atoms. SEM micrographs confirme the defects and stresses with higher degree of crystallinity, and finally the large grains are formed [2, 3, 10, 15].

The SEM micrographs of as-deposited CdS thin films also demonstrates roughness which was reduced as the anneal time of Ag-doped CdS increased. The grains present in asdeposited CdS thin film also became irregular and diverse in sizes, after silver doping. The increase in anneal time also facilitated in triggering the process of coalescence. In II-VI semiconductors, re-crystallizations of grains and its growth are reported and well documented $[1-3,17-26]$.

The investigation of surface roughness was carried out by Atomic Force Microscopy (AFM). AFM images of CdS as-deposited and Ag-doped were presented in Fig. 4 (a-d), Table 1 provides the roughness values of the as-deposited and Ag-doped CdS samples.

\section{Electronic Study}

The effects of Ag-doping on CdS thin films were studied by using x-rap photoelectron spectroscopy (XPS) technique. The Cd-3d, Ag-3d, S-1s, C-1s and O-1s core levels XPS spectra were recorded and analyzed for entire series of samples. Carbon $(\mathrm{C}-1 \mathrm{~s})$ peak was used as a charge reference and de-convoluted by using CASA XPS software. All binding energies were standardized at $284.5 \mathrm{eV}$ for $\mathrm{C}-1 \mathrm{~s}$. The carbon species were due to the effect of $\mathrm{CO}_{2}$ coming from glass substrate or may be due to adsorbents or carbonates of environment [2]. Some of the elements may exist in low level energy and absorbed in baseline. Nonlinear Shirley type back ground was subtracted in all XPS graphs. Here, we are presenting the XPS spectra of few selected samples e.g. as-deposited and $30 \mathrm{~min}$ Ag-doped CdS thin film samples.

The survey scans of as deposited and $30 \mathrm{~min}$ Ag-doped CdS thin film confirmed the presence of $\mathrm{Ag}$ in $\mathrm{CdS}$ thin films as shown in Fig. 5 (a). The S-2p, C-1s, Cd-3d and O-3d peaks at relevant binding energies are highlighted for both samples with additional Ag-3d for 30 minute Ag-doped CdS sample. High resolution core level spectra of Ag-3d was deconvoluted with Lorentzian-Guassian peaks fitting as shown in Fig. 5 (b) to identify the oxidation states of Ag. As the experimental data confirmed the symmetric core level Ag-3d spectra, so the existence of single component of $\mathrm{Ag}$ is obvious. The value of $\mathrm{Ag}-3 \mathrm{~d}_{5 / 2}$ in theory for metallic silver $\left(\mathrm{Ag}^{0}\right)$ is $368.2 \mathrm{eV}$ and the difference of spin orbit coupling of $\mathrm{Ag}$ $3 \mathrm{~d}_{5 / 2}$ and $\mathrm{Ag}-3 \mathrm{~d}_{3 / 2}$ usually remains $6 \mathrm{eV}$ for $\left(\mathrm{Ag}^{0}\right)$ [27-30]. We found the peak positions of $\mathrm{Ag}-3 \mathrm{~d}_{5 / 2}$ and $\mathrm{Ag}-3 \mathrm{~d}_{3 / 2}$ are lies at 375.08 and $369.20 \mathrm{eV}$ respectively for 30 minute $\mathrm{Ag}$-doped CdS thin film sample. The spin orbit coupling $\left(\Delta E=3 d_{5 / 2}-3 d_{3 / 2}\right)$ for Ag was found $5.7 \mathrm{eV}$ for 
our doped sample. Usually, the binding energies of single valance state (e.g. $\mathrm{Ag}^{1+}$ ) is higher than the metallic form of the same species (e.g. $\mathrm{Ag}^{0}$ ) [27-30]. These results reflects that the silver exist in $\mathrm{Ag}^{1+}$ state in our doped samples. Since no metallic silver was observed in the XPS core level spectra so these results do support the XRD findings. Furthermore the $\mathrm{Ag}^{1+}$ states may enhance the optical properties of doped samples as compared to pure sample.

In Fig. 5 (c-d) the oxygen (O-1s) high resolution core level spectra of as deposited $\mathrm{CdS}$ and Ag-doped CdS thin films have been presented. The oxygen peaks were deconvoluted and we found that at the single peak position of $534.55 \mathrm{eV}$ for as deposited sample and for Ag-doped CdS thin films the peak position was $534.53 \mathrm{eV}$. We concluded that the O1s spectra is symmetric so the existence of multiple components of oxygen species are prohibited in our samples. Probably, these O-1s species are due to chemisorption or $\mathrm{OH}$ on surface of the thin films. These peaks may also be due to the surface oxygen adsorb on thin film sites. In literature the theoretical and experimental values of $\mathrm{O} 1 \mathrm{~s}$ lies from $530 \mathrm{eV}$ to $537 \mathrm{eV}$ [26]. The peaks at lower binding energies are due to some bonding oxygen species with parent compounds in oxide based systems, medium binding energies shows the oxygen vacancies concentration due to deficient regions or might be for dissociated oxygen. Some small peaks at binding energies of $537 \mathrm{eV}$ are due to contamination of O-C [2, 27-30]. So, in our case, we found the presence of oxygen only at the surface of thin films in both samples.

The high resolution core level spectra of Cd-3d and S-2p of as-deposited and Agdoped CdS thin films has been demonstrated in Fig. 6 (a-d). The de-convoluted XPS spectra of $\mathrm{Cd}-3 \mathrm{~d}_{5 / 2}$ and $\mathrm{Cd}-3 \mathrm{~d}_{3 / 2}$ of as deposited and Ag-doped CdS were identified after subtracting the Shirley back ground with fitted Lorentzian-Guassian peaks has been revealed in Fig. 6 (a) and (c) respectively. The peak positions for Cd-3d $d_{5 / 2}$ and $C d-3 d_{3 / 2}$ of as deposited CdS thin films were at $406.57 \mathrm{eV}$ and $413.33 \mathrm{eV}$ respectively with spin orbit coupling energy $\Delta \mathrm{E}=$ $6.76 \mathrm{eV}$. While we noticed after incorporating the $\mathrm{Ag}$, the $\mathrm{Cd}-3 \mathrm{~d}_{5 / 2}$ peak was located at $406.63 \mathrm{eV}$ and $\mathrm{Cd}-3 \mathrm{~d}_{3 / 2} \mathrm{eV}$ at $413.21 \mathrm{eV}$ through pin orbit coupling energy $\Delta \mathrm{E}=6.58 \mathrm{eV}$. These results are in good agreement that $\mathrm{Cd}$ exist in $2+$ state and its bonding with $\mathrm{S}^{2-}$ species in both samples. The fitted peaks XPS core spectra of S-2 $\mathrm{p}_{3 / 2}$ of as-deposited and 30 minutes Ag-doped CdS has been recorded and displayed in Fig. 6 (b) and (d) respectively. The states for S-2p had positioned at $162.69 \mathrm{eV}$ for as-deposited CdS while the S-2p was located at $162.21 \mathrm{eV}$ after 30 minutes Ag-doping. The above values are good agreement with earlier reports [28-30]. The slight shift of S-2p was observed after Ag-doping towards lower binding energy. These energies shift were due to Ag immersion into the CdS thin films which may change the chemical environment of the samples. The shift in binding energies of these 
measured value may be due to the $\mathrm{S}$ vacancies. The vacancies of $\mathrm{S}$ was made during the synthesis of CdS thin films in CSS techniques. One S vacancy was attributed to one $\mathrm{S}$ ion,

but for $\mathrm{S}^{2-}$ electronegativity two electrons should be injected. The second electron may enhance the cloud density of Ag-doped CdS thin films. This electron may be responsible of weaker interaction between outer electrons and nucleus and the decreasing trend of binding energies was observed previously [27-30].

\section{Electrical Measurements}

The electrical measurements were performed for the entire series of samples at room temperature. In as-deposited, we found the highest concentration of negative charge carrier (electrons) $5.97 \times 10^{16} / \mathrm{cc}$, while the concentration of electron decreased as Ag incorporates. The lowest electron carrier concentration $\left(2.18 \times 10^{14} / \mathrm{cc}\right)$ has been measured for $30 \mathrm{~min} \mathrm{Ag}$ doped CdS thin film sample. Similarly, the activation energy (Ea) for as-deposited CdS and 30 min Ag-doped CdS has been measured highest 0.424 values and lowest 0.134 values respectively. From electrical measurements, we argued strongly the incorporation of $\mathrm{Ag}^{1+}$ in place of $\mathrm{Cd}^{2+}$ by increasing the hole carrier concentration as the amount of negative charge carrier reduced with increasing the Ag concentration [1-3, 10, 15].

\section{Photoluminescence (PL) Spectroscopy}

Photoluminescence (PL) was used to investigate the Ag-doping defects on CdS thin films. Fig. 7. shows the PL spectra of as-deposited CdS and Ag-doped CdS thin films with the elicitation at $375 \mathrm{~nm}$ of laser. The data points were fitted with Guassian functions. CdS thin films show broad peak at $634 \mathrm{~nm}$ and other peaks are at $544 \mathrm{~nm}, 435 \mathrm{~nm}$, and $399 \mathrm{~nm}$.

In as-deposited CdS thin films, a careful and systematic survey of CdS thin films shows the emission at $399 \mathrm{~nm}$ and $416 \mathrm{~nm}$ correspond to exciton absorption. The $516 \mathrm{~nm}$ relates to the green emission. The emission at $634 \mathrm{~nm}$ indicates the radiative transition in CdS thin films. [29]. The green effects was produced due to the intrinsic defect during fabrication process [30], it is also due to thickness variation of CdS thin films. The shifting of broad peak towards high energy level might be due to increase in grain sizes after immersion and this size change is similar to exciton of PL, well documented earlier [30]. The quantum confinement of electrons and holes also reported with exciton of PL. The electron quantum confinement has significant role as compared to holes quantum confinement because shift in energy for energy of holes is less than the electron's energy. The size dependence of exciton 
PL energy also confirmed with this energy shift as the holes are localized in acceptors and electron quantum confinement is due to broad PL peak shift and delocalized [29]. On concluding note the size change in grains are related to quantum confinement effects.

In Ag-doped CdS thin films the strong emission peak was at $416 \mathrm{~nm}$ and other peak at $516 \mathrm{~nm}$. The intense and broad peak at $634 \mathrm{~nm}$ shifted towards lower wavelength of $416 \mathrm{~nm}$ after Ag-doping, which corresponds to the exciton emission. The discussion on size dependence of grains on as-deposited CdS thin films is similar for Ag-doped CdS samples. The radiative recombination between localized holes and delocalized electrons would be due to the broad PL peak. The PL decay dynamics would be helpful for further study of broad peak mechanism in as-deposited and Ag-doped CdS thin films. The PL decay is nonexponential with decay energy relates to PL energy, at high photon energies the PL intensity decaying rapidly.

The phenomenon of spin-orbit coupling and crystal field interaction can be studied in as-deposited $\mathrm{CdS}$ and $\mathrm{Ag}$-doped $\mathrm{CdS}$ thin film samples. The valence band of as-deposited $\mathrm{CdS}$ thin films splits into four sub-shells, indicating four exciton energy levels $\mathrm{E}_{\mathrm{a}}=3.10 \mathrm{eV}$, $\mathrm{E}_{\mathrm{b}}=2.85 \mathrm{eV}, \mathrm{E}_{\mathrm{c}}=2.28 \mathrm{eV}$ and $\mathrm{E}_{\mathrm{d}}=1.95 \mathrm{eV}$. These emission peaks shows the excitons bound to neutral acceptors and exciton bound to neutral donors. Whereas, in Ag-doped CdS thin films two sub-shells observed due to valence band splitting. $\mathrm{E}_{\mathrm{a}}=2.98 \mathrm{eV}$ and $\mathrm{E}_{\mathrm{b}}=2.4$ $\mathrm{eV} . \mathrm{E}_{\mathrm{b}}=2.4 \mathrm{eV}$ in Ag-doped $\mathrm{CdS}$ thin films might be due to sulfur vacancies in valence band. The $\mathrm{E}_{\mathrm{c}}=2.28 \mathrm{eV}$ in as-deposited $\mathrm{CdS}$ thin films and $\mathrm{E}_{\mathrm{b}}=2.4 \mathrm{eV}$ for Ag-doped CdS relates to the energy band gap of the films also discussed in transmission section.

Finally, the room temperature PL study indicates the changes observed in asdeposited and Ag-doped CdS thin films to investigate the optical properties. The active recombination centers in CdS thin films using PL probes, in which some of them are responsible for photocurrent loss in window layer due to optical absorption. The defects and impurity acts as a recombination center for charge carrier, reason for PV conversion efficiency. In n-type CdS window layer photo-generated, part of carriers does not produce photo-current due to non-radiative or radiative recombination. At the end, $\mathrm{CdS}$ thin films are highly compensating with comparable density of deep acceptors state and shallow donor states $[29,30]$.

\section{Optical Study}


Transmission percentage spectra versus wavelength $(T-\lambda)$ for the entire series of sample from 300-2100 nm range has been presented in Fig. 8 (a-d). The effects of Ag-doping in CdS thin films for determining the optical properties i.e. room temperature transmittance in percentage and band gap has been analyzed here. The $\mathrm{CdS}$ thin films exhibit a strong absorption in the UV region, and a transmission ranging from 60 to $90 \%$ in the visible and IR regions, respectively. The optical parameters including refractive index $(n)$, absorption coefficient $(\alpha)$ and optical thickness $(d)$ were calculated using Swanepoel model [1-3, 5, 10, 22], namely

$$
T=\frac{A x}{B-C x \cos (\varphi)+D x^{2}}
$$

where, refractive index of air is fixed at 1.0. $A=16 \times n^{2} s, B=(n+1)^{3} \times\left(n+s^{2}\right), C=$ $2 \times\left(n^{2}-1\right) \times\left(n^{2}-s^{2}\right), D=(n-1)^{3} \times\left(n-s^{2}\right), \Phi=4 \pi n d / \lambda, x=\exp (-\alpha d)$, and $k=\alpha \lambda / 4 \pi$. In Eq. $2 n$ and $s$ are refractive indices of film and glass, respectively, $k$ and $\alpha$ are extinction and absorption coefficients, respectively, $d$ is thickness of the film and $\lambda$ is known as wavelength. The calculation for refractive index was carried out using the relation, $n=a+b / \lambda^{2}$, where ' $a$ ' and ' $b$ ' are two constants. The above parameters were used for theoretical curve fitting on experimental data. There was no significance difference in the refractive indexes of as-deposited and Ag-doped films - for the former case, it was 2.25, and for the later with Ag-doping its was found out to be 2.26 at $400 \mathrm{~nm}$ wavelength as presented in Fig. 9. for the variation of refractive index as the function of wavelength.

The absorption process of the films is complex and may be due to light scattering in transparent regions, defect absorption, multi-phonon absorption, or Urbach tail $[10,15,16]$. For the minimum absorption energy of photon from any absorption line, Taylor series is used, where $\alpha$ can be calculated by the relation, $\alpha=c+f / \lambda+g / \lambda^{2}+\ldots, \quad f, g, \ldots$. being the constants).The calculation of $\alpha$ in high absorption region can be done by using curve fitting on $n$ and $d$. In high absorption region and the medium absorption regions, solution for $x$ is given by the Eq. 3 .

$$
x=\frac{\left(C^{\prime}+A / T\right)-\left(\left(C^{\prime}+A / T\right)^{2}-4 B D\right)^{1 / 2}}{2 D}
$$

Here $\alpha=-\ln (x) / d$, and $C^{\prime}=\mathrm{C} \times \cos \Phi$.

Ag-doped CdS showed variations in the transmission and energy band gap, calculated by Eq. 4., that is,

$$
\alpha h v=A\left(h v-E_{g}\right)^{N / 2}
$$


where, $h v$ is the photon energy. Theabsorption coefficient can also be calculated by the relation, $\alpha=\ln (1 / T) / d$, where, transmittance is obtained by $T=\frac{\% T}{100}[2,4,20]$. Now, Eq. 5 . can be used to calculate thickness, $d$, of the thin film, namely

$$
d=\frac{\lambda_{\text {max }} \lambda_{\text {min }}}{4 n\left(\lambda_{\text {max }}-\lambda_{\text {min }}\right)}
$$

where, subscript min and max denotes the minimum and maximum wavelength (in nano meters) extracted from transmission graphs. The thickness varied from $283 \mathrm{~nm}$ to $541 \mathrm{~nm}$ in as-deposited CdS thin films to $30 \mathrm{~min} \mathrm{Ag}$-doped CdS thin films samples.

The band gap calculation for as-deposited CdS and Ag-doped films are shown in Fig. 10 (a-d). Notice that there is a significant increase in the energy band gap due to Ag-doping the energy band gap was increased from the value of $2.15 \mathrm{eV}$ to $2.45 \mathrm{eV}$. The values of energy band gap cross ponds to $577 \mathrm{~nm}$ and $506 \mathrm{~nm}$ which showed the green to blue shift in energy. The significant increase in the energy band gap might be due to defects generation with in energy band gap as the Fermi level is changed after doping. As, we observed that the band gap enhanced as $\mathrm{Ag}^{1+}$ incorporated and replaced the $\mathrm{Cd}^{2+}$ as substitutional defects. The transmittance decreased after Ag-doping but energy band gap enhanced also the transition type is direct, which shows suitability and sustainability for window layer in II generation solar cells.

\section{Conclusions}

CdS non-structured thin films have been synthesized by CSS technique and Ag was immersed in it by using ion exchange process. Synthesis by using CSS techniques played a vital role in the physical properties. The XRD of Ag-doped CdS thin films exhibited cubic structure. SEM micrographs helped to observe the variation in grain size before and after $\mathrm{Ag}$ immersion. Optically Ag-doped CdS thin films are suitable for window layer with low resistivity. The values of wavelength for energy band gap vary from $577 \mathrm{~nm}$ to $506 \mathrm{~nm}$, which showed the green to blue shift in energy. The significant increase in the energy band gap might be due to defects generation with in energy band gap as the fermi level is changed after Ag-doping. We observed that the band gap enhanced as $\mathrm{Ag}^{1+}$ was incorporated and replaced the $\mathrm{Cd}^{2+}$ as substitutional defects. The band gap change is slight where as a large difference in electrical resistivity was achieved from $10^{6} \Omega-\mathrm{cm}$ to $10^{2} \Omega-\mathrm{cm}$. The type of conductivity of CdS thin films were n-type after immersion of Ag. Ag-doped CdS thin films have stability as well as sustainability discussed in XPS section as $\mathrm{Ag}^{+}$may enhance the 
stability of Ag-doped CdS thin films. The energy band gap engineering for tenability of their optical properties can be controlled by Ag-doping, which showed a change in band gap of asdeposited CdS thin films after Ag-doping.

\section{Acknowledgements}

International Research Support Initiative Program (IRSIP) of Higher Education Commission (HEC) Islamabad-Pakistan is acknowledged through Pin \# IRSIP 23 Ps 15 and travel grant funds for presentation of research work through 269.129/TG/R\&D/HEC/2017/21895. Dr. Zulfiqar Ali is thanked from Optics Laboratories (O-Labs) PINSTECH for optical characterizations. Dr. Ahmed Shuja Syed and Engr. M. Ali from Centre for Advanced Electronics \& Photovoltaic Engineering (CAEPE), IIU-Islamabad is acknowledged for electrical characterizations.

\section{References}

[1] N. A. Shah, W. Mahmood, Thin Solid Films, 544 (2013) 307-312.

[2] W. Mahmood, A. Thomas, A. Haq, N. A. Shah, M. F. Nasir, J. Phys. D: Appl. Phys., 50 (2017) 255503-7.

[3] W. Mahmood, N. A. Shah, Opt. Mater., 36 (2014) 1449-1453.

[4] M. Urbanczyk, W. Jakubik, E. Maciak, J. Mol. Q. Acou. 26 (2005) 273.

[5] W. Mahmood, N. A. Shah, American Institute of Physics (AIP), 1476 (2012) 178182.

[6] W. Zheng, P. B. Griffin, J. McVittie, S. Wong, P. C. McIntyre, Y. Nishi, IEEE Electron Device Lett. 28 (2007) 14-16.

[7] S. V. Averin, P. I. Kuznetsov, V. A. Zhitov, N. V. Alkeev, V. M. Kotov, L. Y. Zakharov, N. B. Gladysheva, Tech. Phys. 57 (2012) 1514-1518.

[8] R. N. Bhattacharya, M. A. Contreras, B. Egaas, R. N. Noufi, Appl. Phys. Lett. 89 (2006) 253503-06.

[9] I. O. Oladeji, L. Chow, Thin Solid Films 474 (2005) 77-83.

[10] Waqar Mahmood, Junaid Ali, Iqra Zahid, Andrew Thomas, Anwar ul Haq, Optik 158 (2018) 1558-1566.

[11] X. Wu, Sol, Energy, 77 (2004) 803.

[12] T. D. Dzhafarov, F. Ongul, I. Karabay, J. Phys. D: Appl. Phys. 39 (2006) 3221.

A. Ishizumi Y. Kanemitsu, J. Phys. Soci. Japan, 79 (2010).

[13] Waqar Mahmood, A. Haq, M. Anis ur Rehman, Iran J Sci Technol Trans Sci., doi: 10.1007/s40995-018-0605-x.

[14] V. Kapaklis, P. Poulopoulos, V. Karoutsos, T. Manouras, C. Politis, Thin Solid Films 510 (2006) 138-143..

[15] W. Mahmood, N. A. Shah, Curr. Appl. Phys., 14 (2014) 282-286. 
[16] W. Mahmood, N. A. Shah, S. Akram, U. Mehboob, U. S. Malik, M. U. Sharaf, Chalcogenide Letters, 10 (2013) 273 - 281.

[17] R. W. Birkmire, B. E. McCandless, S. S. Hegedus, Int. J. Solar Ener. 1(1992) 145.

[18] T. Aramoto, S. Kumusawa. Jpn. J. Appl. Phys. 36 (1997) 6304.

[19] I. Moriguchi, I. Tanaka, Y. Teraoka, S. J. Kagawa, Chem. Soc. Chem. Commun. 19 (1991) 1401-1402.

[20] E. Vasco, E. Puron, O. De Melo, Mater. Lett. 25 (1995) 205.

[21] S. Aksay, M. Polat, T. Özer, S. Köse, G. Gürbüz, Applied Surface Science 257 (2011) $10072-10077$.

[22] R. Swanepoel, J. Phys. E: Sci. Instrum. 6 (1983) 1214-1218.

[23] M. Ristovaa, M. Ristov, Appl. Surf. Sci., 181 (2001) 68- 77.

[24] S. Huang, Y. Lin, J. Yang, X. Li, J. Zhang, J. Yu, H. Shi, W. Wang, Y. Yu, RSC Adv., 3 (2013) 20782-92.

[25] M. L. Pang, J. Y. Hu, H. C. Zeng, J. Am. Chem. Soc., 132 (2010) 10771-75.

[26] S. Sen S. Mahanty, S. Roy, O. Heintz, S. Bourgeois, D. Chaumont, Thin Solid Films, 474 (2005) 245-249.

[27] S. Huang, Y. Lin, J. Yang, X. Li, J. Zhang, J. Yu, H. Shi, W. Wang, Y. Yu, RSC Adv., 3 (2013) 20782-20792.

[28] M. L. Pang, J. Y. Hu, H. C. Zeng, J. Am. Chem. Soc., 132 (2010) 10771.

[29] Chuan $\mathrm{Hu}$, Xianghua Zeng, Jieya Cui, Haitao Chen, and Junfeng LuJ. Phys. Chem. C 117 (2013) 20998-21005.

[30] Hidekazu Kato, Jun Sato, Takashi Abe, Yasube Kashiwaba, Phys. stat. sol. (c) 1 (4) (2004) 653-656. 


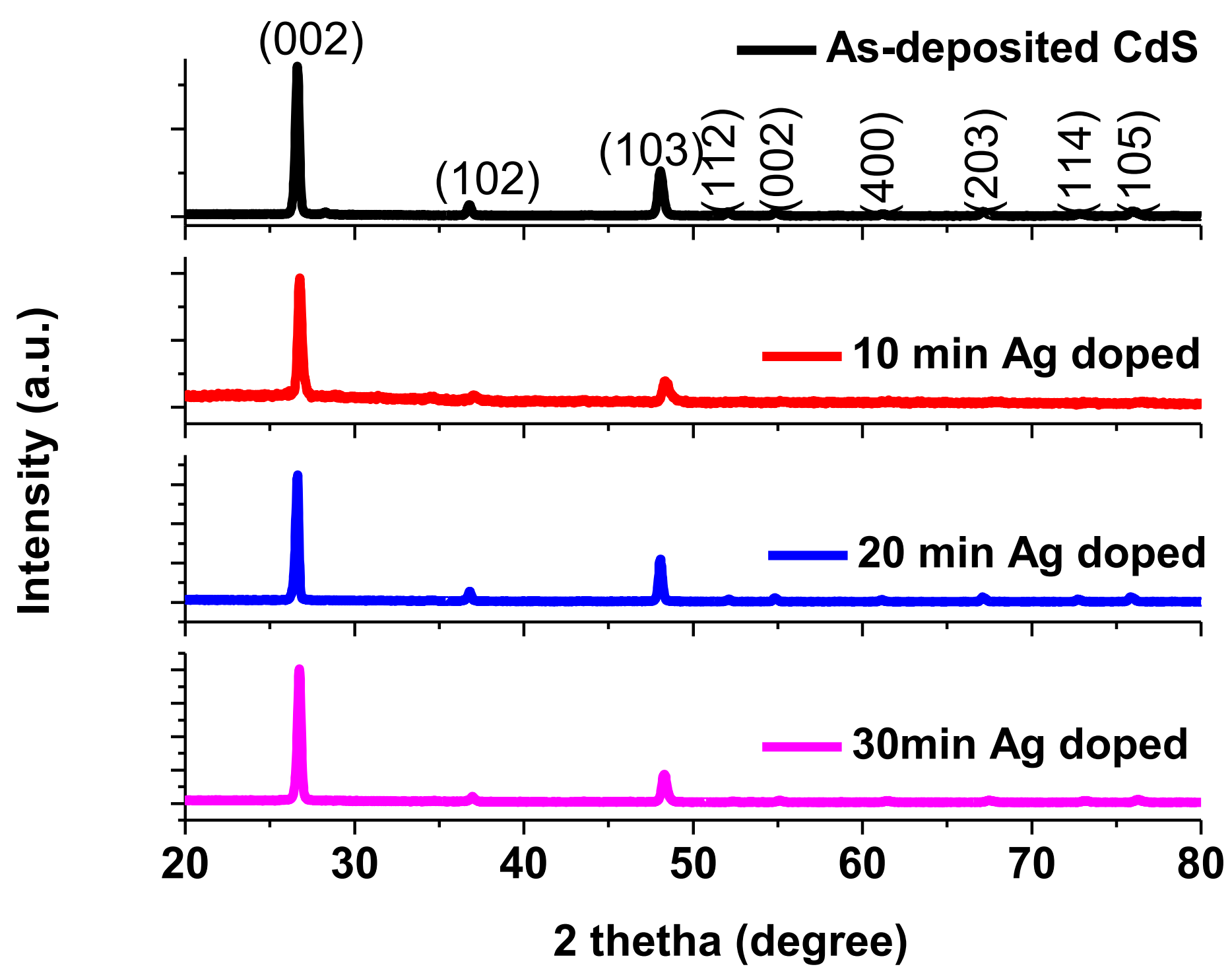

Figure 1: $\quad$ XRD patterns of as-deposited and Ag-doped CdS thin films for various doping time 

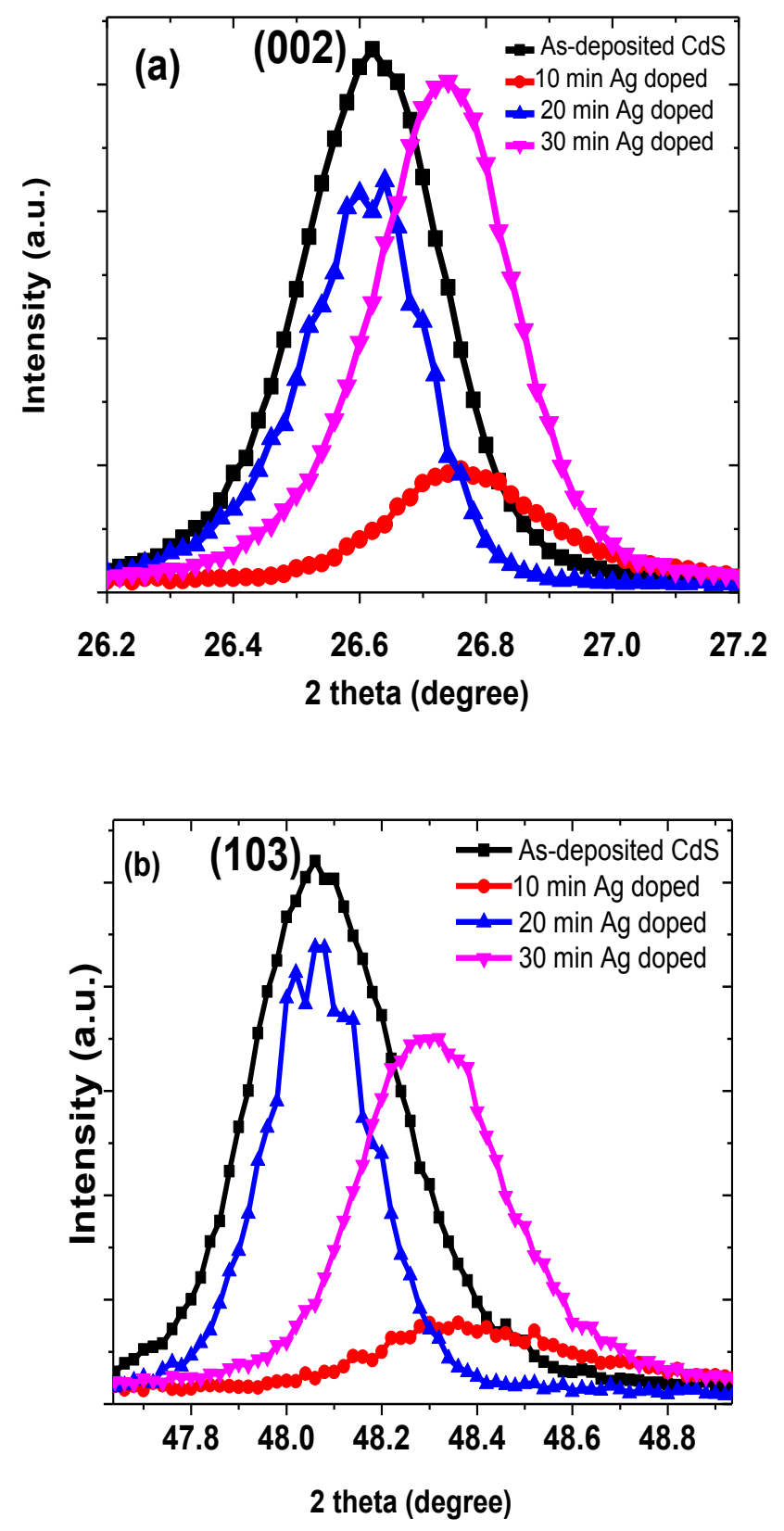

Figure 2: $\quad$ Shifted (a) (002) planes (b) shifted (103) planes for entire series of CdS samples 

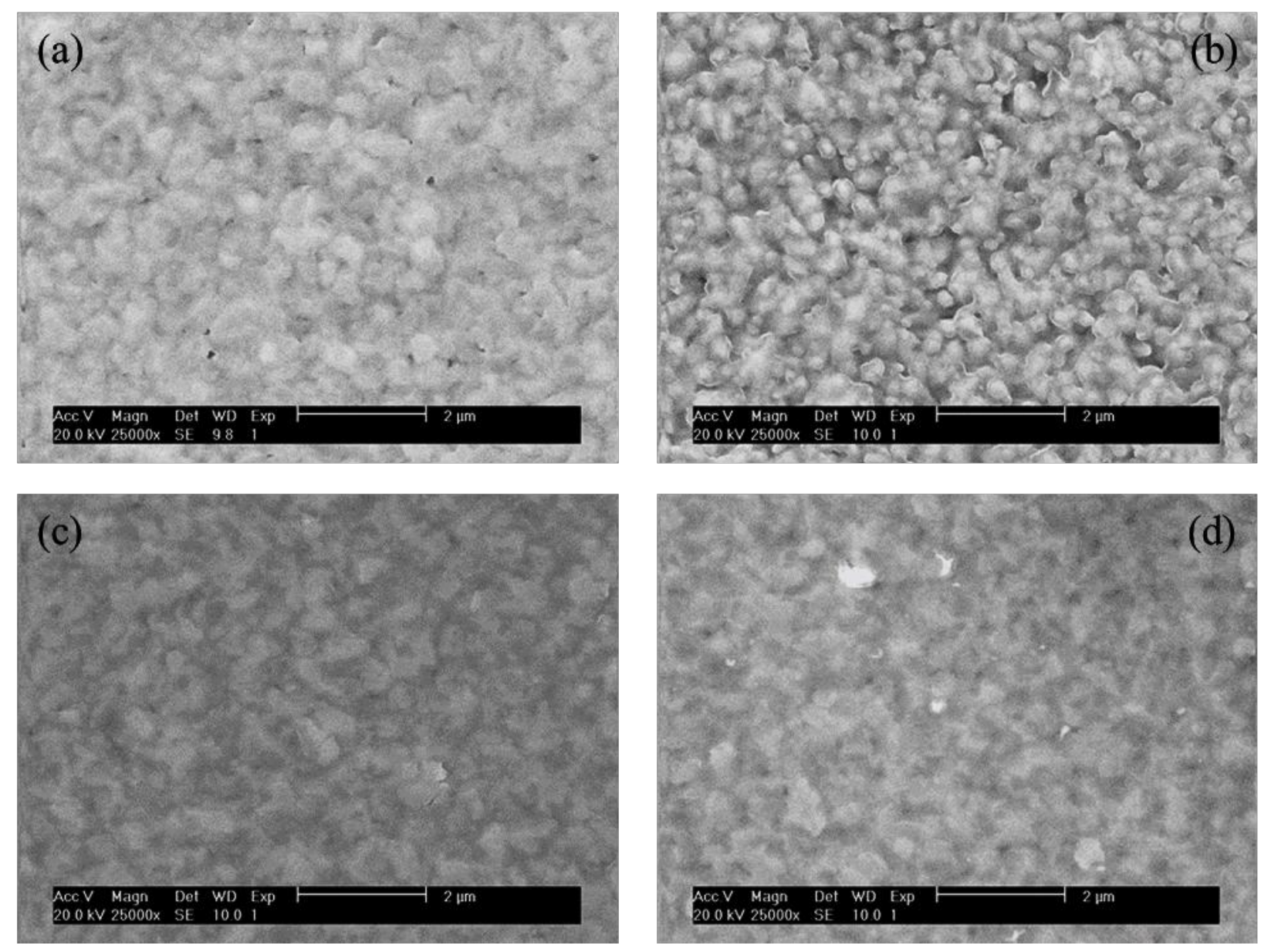

Figure 3: $\quad$ SEM images of (a) As-deposited CdS (b) 10 min Ag doped CdS (c) 20 min Ag doped CdS (d) 30 min Ag doped CdS 

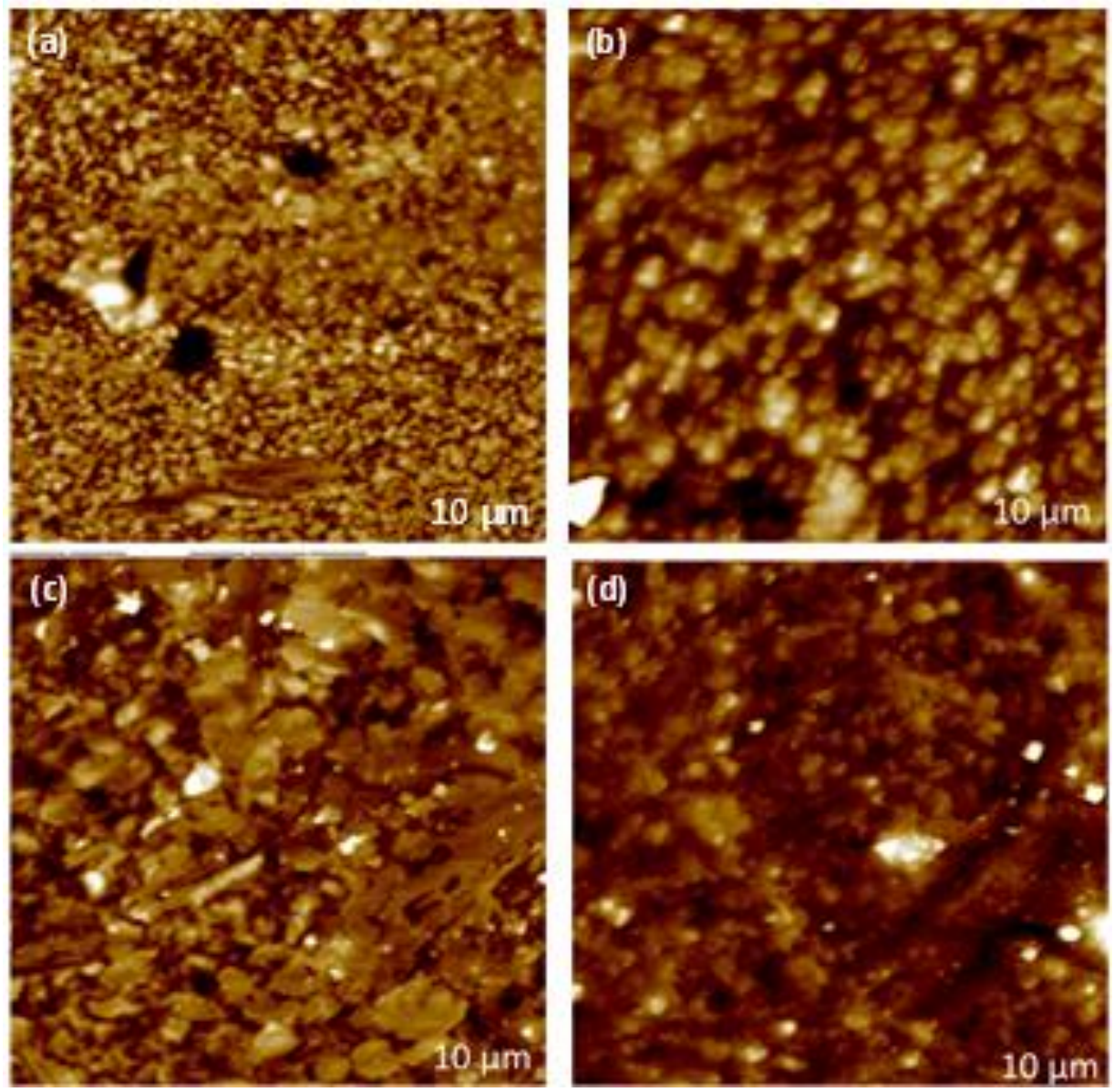

Figure 4: $\quad$ AFM images of (a) As-deposited CdS (b) 10 min Ag doped CdS (c) 20 min Ag doped CdS (d) 30 min Ag doped CdS 

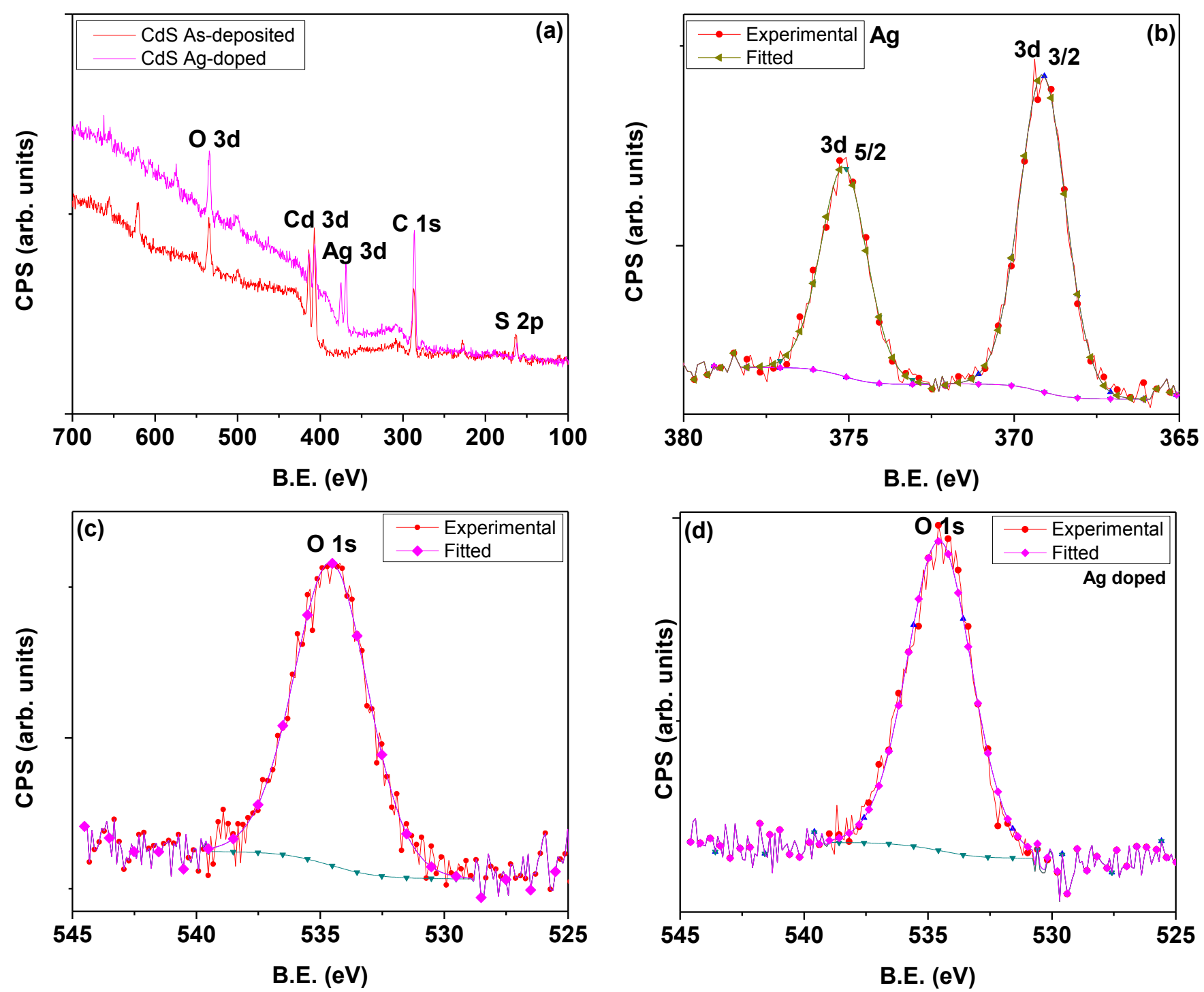
Figure 5: (a) Survey scans (b) Ag- $3 d$ scans of 30 minute Ag doped CdS thin film sample (c) Oxygen scan of as-deposited thin film sample (d) Oxygen scan of Ag-doped CdS thin films sample 

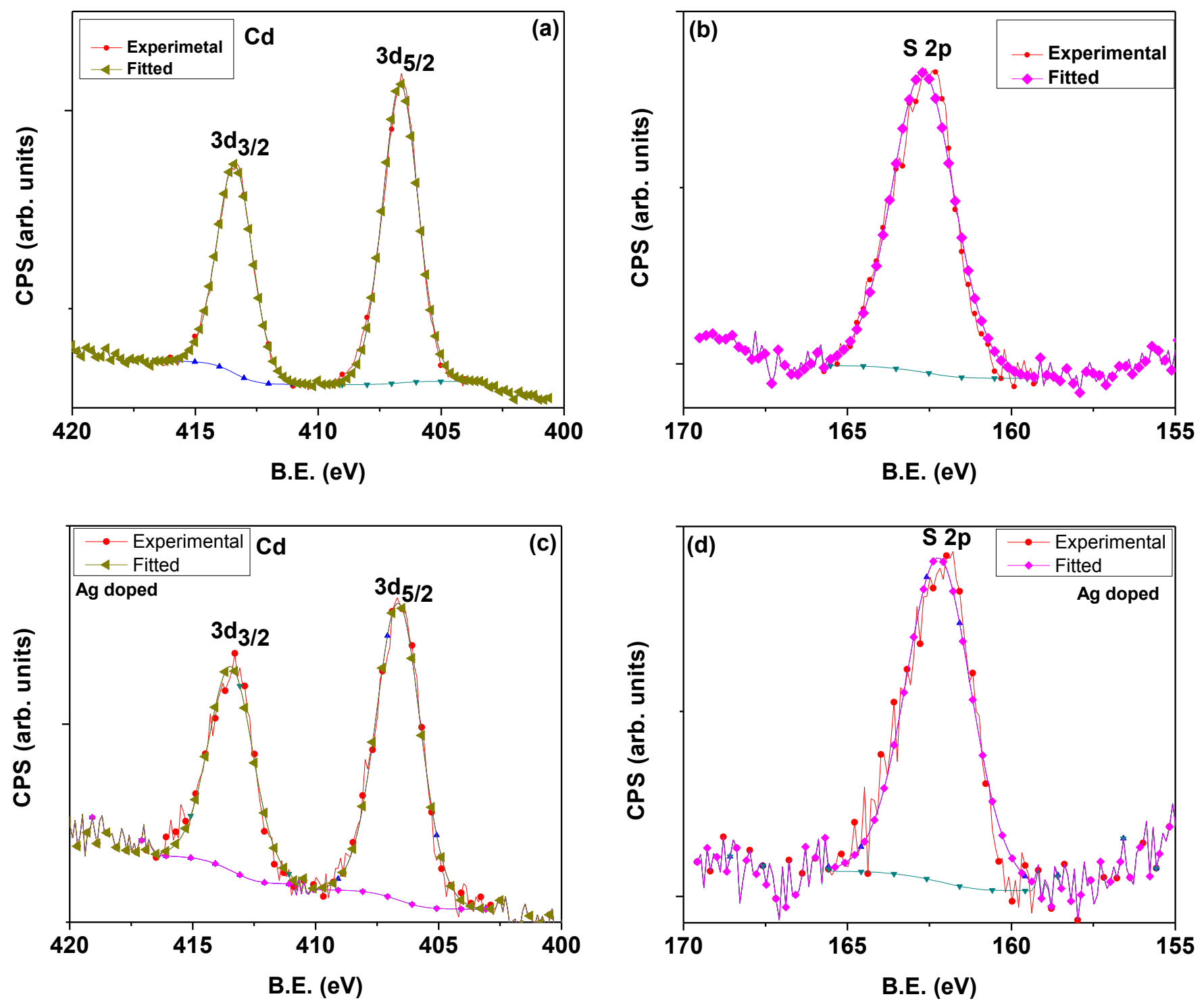
Figure 6: (a) Cd-3d scans of as-deposited CdS thin film sample (b) $\mathrm{S}-2 p$ scans of asdeposited CdS thin film sample (c) Cd-3d scans of 30 min Ag-doped CdS thin film sample (d) S-2p scans of 30 min Ag-doped CdS thin films sample

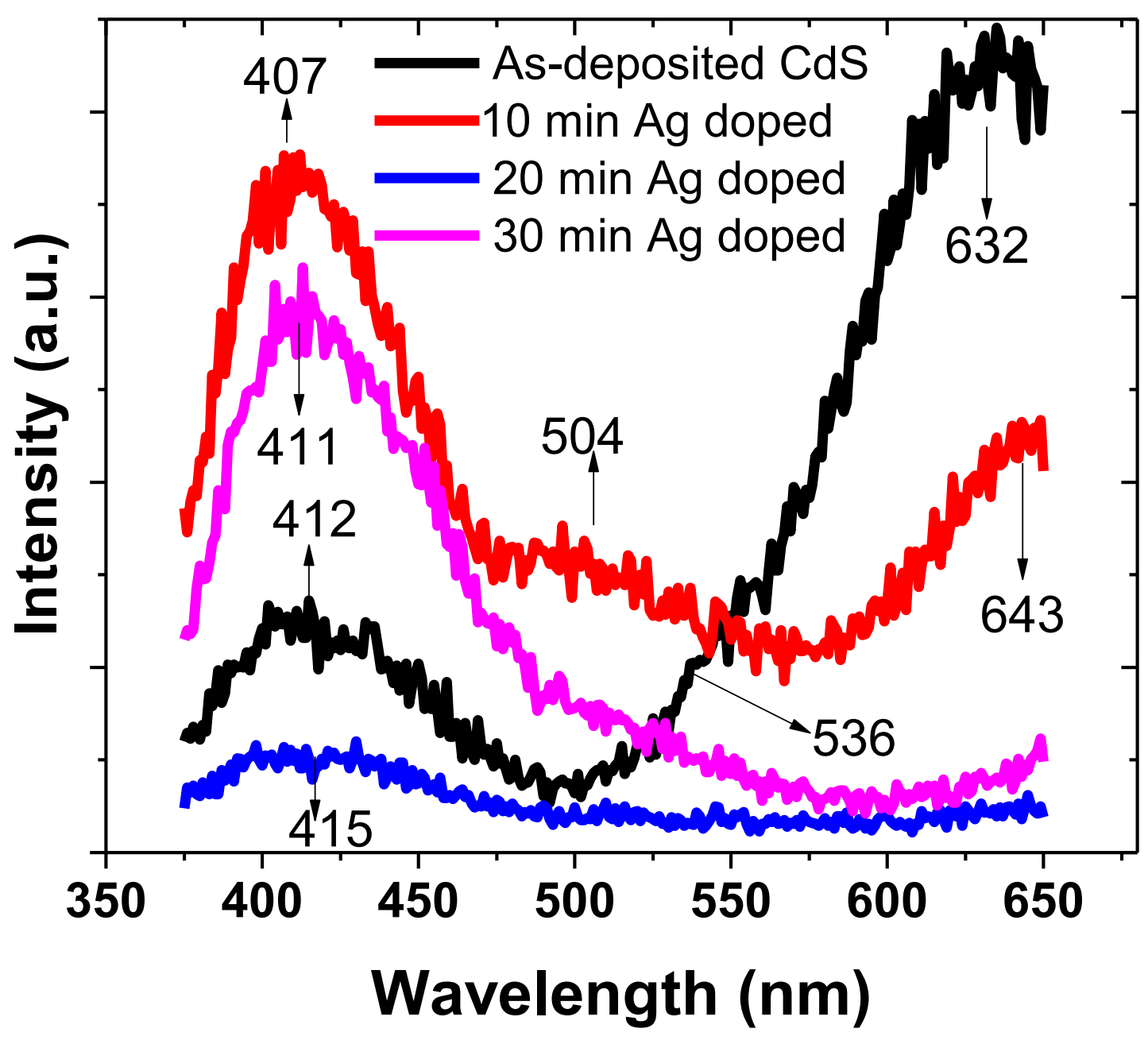


Figure 7: $\quad$ Room temperature photoluminescence (PL) spectra of As-deposited CdS and Ag doped CdS thin film samples. 

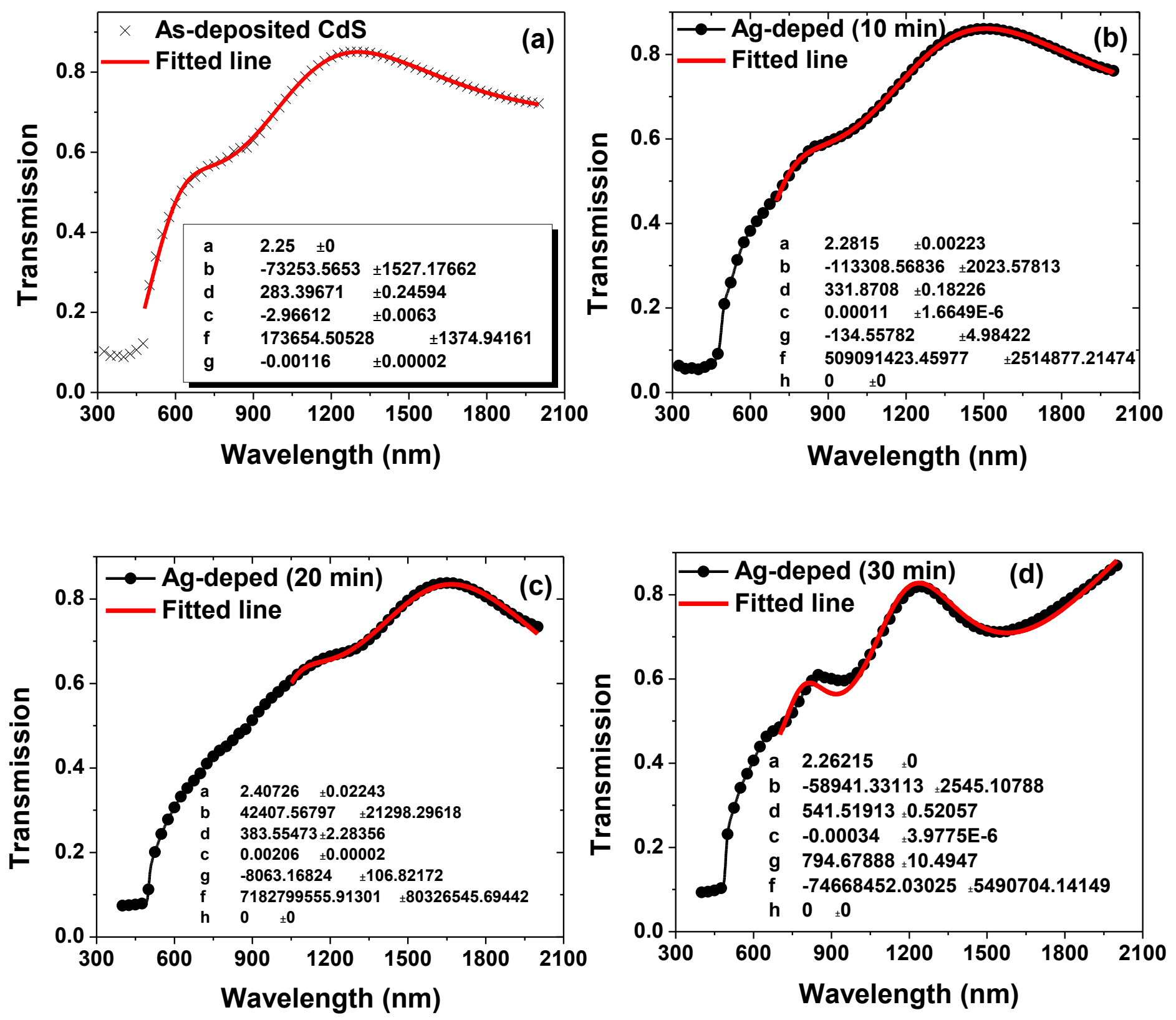

Figure 8: $\quad$ Transmission vs. wavelength of (a) As-deposited CdS (b) 10 min Ag-doped CdS (c) 20 min Ag-doped CdS (d) 30 min Ag-doped CdS 


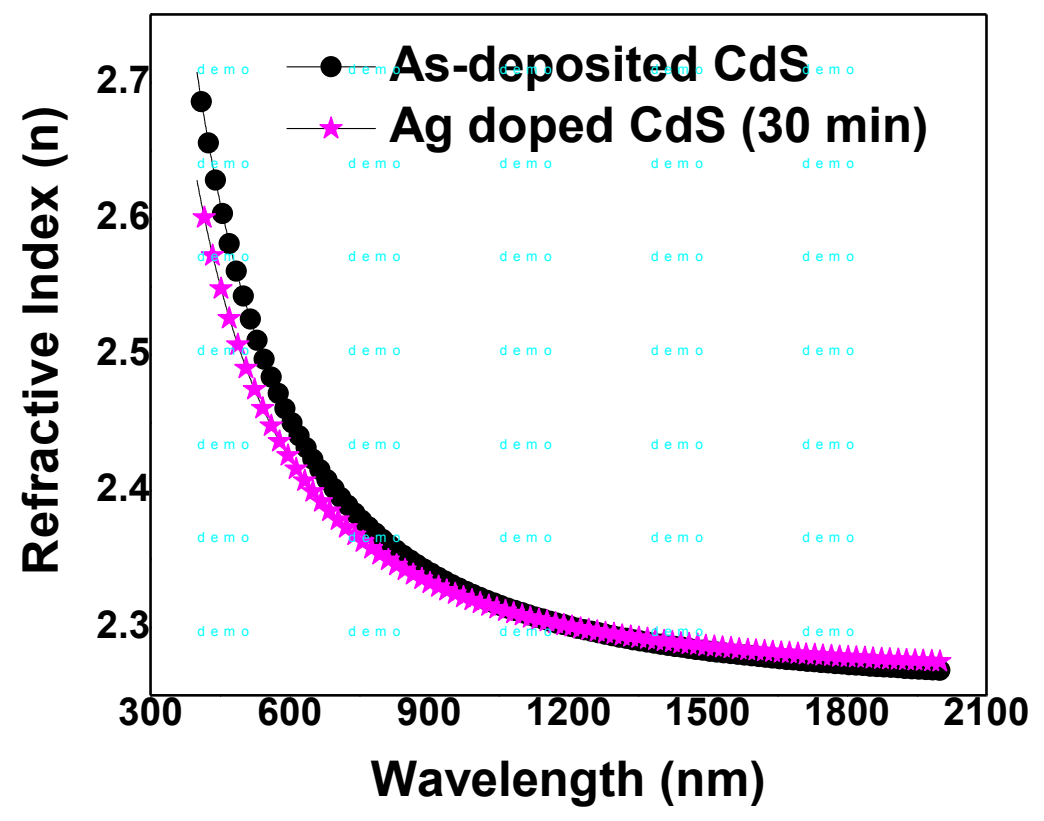

Figure 9: Refractive index of As-deposited and 30 min Ag doped CdS thin film samples. 

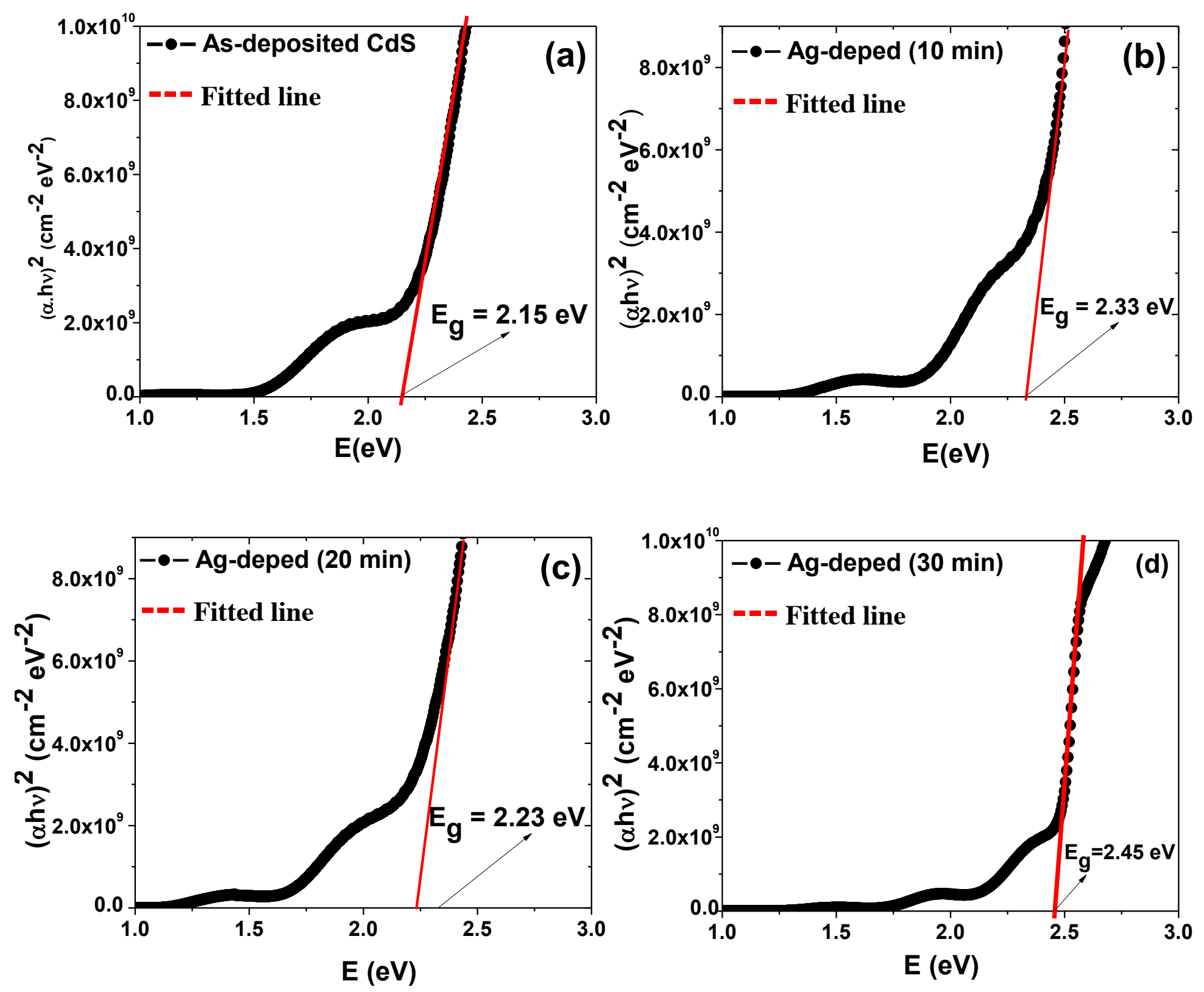
Figure 10: $\quad$ Energy band gap of (a) As-deposited CdS (b) 10 min Ag-doped CdS sample (c) 20 min Ag-doped CdS sample (d) 30 min Ag-doped CdS sample 
Roughness calculation of As-deposited CdS thin films.

\begin{tabular}{ccccccc}
\hline & Rep 1 & Rep 2 & Rep 3 & Mean & SD & RSD \\
\hline $\mathbf{R}_{\mathbf{q}}$ & 20.4 & 23.0 & 24.2 & 22.5 & 1.9 & 8.6 \\
$\mathbf{R}_{\mathbf{a}}$ & 16.4 & 18.7 & 19.4 & 18.2 & 1.6 & 8.6 \\
$\mathbf{R}_{\mathbf{m a x}}$ & 112.0 & 136.0 & 157.0 & 135.0 & 22.5 & 16.7 \\
\hline
\end{tabular}

Roughness calculation of 10 min Ag doped CdS samples.

\begin{tabular}{ccccccc}
\hline & Rep 1 & Rep 2 & Rep 3 & Mean & SD & RSD \\
\hline $\mathbf{R}_{\mathbf{q}}$ & 10.9 & 13.8 & 12.0 & 12.2 & 1.5 & 12.0 \\
$\mathbf{R}_{\mathbf{a}}$ & 8.6 & 10.8 & 9.3 & 9.5 & 1.1 & 12.0 \\
$\mathbf{R}_{\max }$ & 70.6 & 72.4 & 74.6 & 72.5 & 2.0 & 2.8 \\
\hline
\end{tabular}

Roughness calculation of 20 min Ag doped CdS samples.

\begin{tabular}{ccccccc}
\hline & Rep 1 & Rep 2 & Rep 3 & Mean & SD & RSD \\
\hline $\mathbf{R}_{\mathbf{q}}$ & 20.1 & 18.8 & 21.2 & 20.0 & 1.2 & 6.0 \\
$\mathbf{R}_{\mathbf{a}}$ & 15.4 & 13.8 & 17.0 & 15.4 & 1.6 & 10.4 \\
$\mathbf{R}_{\mathbf{m a x}}$ & 118.0 & 137.0 & 126.0 & 127.0 & 9.5 & 7.5 \\
\hline
\end{tabular}

Roughness calculation of 30 min Ag doped CdS samples.

\begin{tabular}{ccccccc}
\hline & Rep 1 & Rep 2 & Rep 3 & Mean & SD & RSD \\
\hline $\mathbf{R}_{\mathbf{q}}$ & 17.8 & 19.7 & 19.4 & 19.0 & 1.0 & 5.4 \\
$\mathbf{R}_{\mathbf{a}}$ & 14.0 & 15.5 & 14.7 & 14.7 & 0.8 & 5.1 \\
$\mathbf{R}_{\max }$ & 93.3 & 103.0 & 116.0 & 104.1 & 11.4 & 10.9 \\
\hline
\end{tabular}

